\title{
What is the impact of kelp forest density and/or area on fisheries?
}

Rita M Araujo ${ }^{1 *}$, Inka Bartsch ${ }^{2}$, Trine Bekkby ${ }^{3,4}$, Karim Erzini ${ }^{5}$ and Isbel Sousa-Pinto ${ }^{1,6}$

\begin{abstract}
Background: Kelp forests are highly productive ecosystem engineers of rocky cold-water marine coastlines, providing shelter, habitat and food for a variety of associated organisms. Several factors have been related with an observed trend of kelp deforestation in some regions of the globe. The effect of this trend on fisheries has been poorly studied. The European directives addressing the conservation of marine habitats highlight the need to increase the knowledge about the relationship between kelp forests and fisheries, which will also be very valuable for the definition of fisheries management measures. This protocol describes the methods that will be used to conduct a systematic review to answer the following question: What is the impact of changes in kelp forest density and/or area on the abundance and diversity of fisheries?

Methods/design: This systematic review will be focused primary in studies that report on positive, negative or no quantitative relationships between kelp forests (abundance and/or presence) and the health of fisheries (including adults and young life stages). The measurement of fisheries health will include abundance, presence and diversity of fisheries, mortality, fertility and recruitment rates and feeding behavior.
\end{abstract}

Keywords: Kelp forests, Ecosystem conservation, Ecosystem services, Fisheries

\section{Background}

Conservation and ecosystem-based management should take account of the contribution of coastal habitats to the functioning of marine ecosystems (Crowder and Norse [1]). Kelp forests are key components of coastal ecosystems and contribute greatly to species richness, and function as a reserve of biodiversity (Steneck et al. [2]). These are highly productive ecosystem engineers of rocky cold-water marine coastlines, hosting a high diversity of species, including fish, mammals, invertebrates, other seaweeds and epibiota (Steneck et al. [2]; Lorentsen et al. [3]). Many of these organisms are linked to the presence of kelp species (large brown algae) through a variety of trophic and habitat associations (Graham [4]). This is the case for numerous species of fishes that use the kelp forests as feeding and nursery areas, and as a shelter from large predators (Norderhaug et al. [5]; Reisewitz et al. [6]). Thus, it is expected that changes in the abundance of kelp forest will affect fish abundance.

\footnotetext{
* Correspondence: ritaraujo@ciimar.up.pt

${ }^{1}$ Centre of Marine and Environmental Research, University of Porto (CIMAR-Porto), Rua dos Bragas, 289, 4050-123 Porto, Portugal

Full list of author information is available at the end of the article
}

Kelp forests also play an important role on coastal defense by damping waves and on carbon sequestration that is used directly by grazers or made available through the detritivorous food webs based on macroalgae (Duggins et al. 1990). Over the past two centuries, overfishing and extirpation of highly valued vertebrate apex predators have led to an increase in sea urchin abundances, promoting a widespread decline of kelp forests (Steneck et al. [2]). Losses in kelp forest systems associated with climate change have also been reported over the last decades, specially near the low latitude limits of kelp ranges where they can become eco-physiologically stressed (Steneck et al. [2]). Other factors reported as locally affecting kelp forest abundances are kelp harvesting, decline of water quality (pollution, eutrophication, sedimentation), diseases and invasive species (Steneck et al. [2]).

The impact of fishing in kelp forests systems, by removing top-predators and enhancing the abundance of herbivores is well documented (Fujita [7], Davenport and Anderson 2007). The increase in herbivorous densities has a negative effect on the abundance of subtidal kelp forests. This affects the detrital food web which generates much of the small invertebrate that fish eat
C Biomed Central

(c) 2013 Araujo et al.; licensee BioMed Central Ltd. This is an Open Access article distributed under the terms of the Creative Commons Attribution License (http://creativecommons.org/licenses/by/2.0), which permits unrestricted use, distribution, and reproduction in any medium, provided the original work is properly cited. 
(Laur and Ebeling 1983). Spatial and temporal variations in kelp abundances have also documented effects on fish recruitment (Carr 1994, O'Connor and Anderson 2010) and densities of older life stages (O'Connor and Anderson 2010). However, less knowledge is available about the impact of kelp forests density and/or area on fisheries.

This information is very valuable in the context of fisheries policies and in the context of several European directives that take into consideration the conservation of marine habitats. Among these, is the Water Framework Directive that establishes a legal framework to protect and restore clean water across Europe and ensure its long-term and sustainable use. This directive links with the Marine Strategy Framework Directive with the objective of ensuring the "good environmental status" of all of Europe's marine regions and sub-regions. The Habitats Directive has as a main objective the maintenance or restoration of protected habitats and species listed in the Annexes at a favourable conservation status. In this context, this directive identifies as natural habitats with community interest the coastal and halophytic habitats that include reefs. Application of the Habitats Directive to the marine environment through the Natura 2000 network represents a key challenge for the EU biodiversity policy. Marine sites of the Natura 2000 network will provide protection, among others, to the habitats listed in Annex I of the Habitats directive including open seas and tidal areas (which include reefs), species listed in Annex II and marine species listed in Annexes IV and $\mathrm{V}$. However, none of the marine species listed belongs to the benthic communities inhabiting reefs. These include primary producers, like kelp species, which condition might importantly affect other marine species listed in the habitats directive like fish species.

This systematic review will provide policy makers with a compilation of knowledge, based on the best available evidence, about the relationship between kelp forests status (area and/or density) and fisheries. This information will be of importance for the definition of the management and conservation policies in coastal ecosystems.

\section{Objective of the review}

The main objective of this review is to provide policy makers with the available evidence about the impact of changes in kelp forest density and/or area on fisheries.

\section{Primary question}

What is the impact of changes in kelp forest density and/or area on the abundance and diversity of fisheries?

Population - Defined marine areas (NB 'Population' is statistical not biological).

Exposure - Changes in Kelp forest density/area.

Comparator - Different densities/areas of kelp forest.
Outcome(s) - Indicators of change in health (abundance of adult and young life stages and diversity) of fish communities.

\section{Methods \\ Searches}

This search aims to integrate the most relevant sources of information to the studied subject including published literature, grey literature and reports. Different sources of information will be searched divided in two categories (databases and search engines) in order to maximize the coverage of the search.

Databases search: the following databases will be considered:

ISI Web of Knowledge (searched by topic)

Electronic Databases available through the Virtual

Library of the University of O'Porto (Springer, Elsevier,

Science Direct)

Directory of Open Access Journals

Only English, French, Spanish and Portuguese written documents will be considered.

Internet search: the following sites will be considered

Google scholar

Scirus

Only the first English, French, Spanish or Portuguese written 50 records will be considered.

\section{Additional sources of information}

Other sources of information will include unpublished reports and published works not assessed through the available sources of information if identified as relevant by a group of selected experts in the field. These articles will be requested directly from the authors or organizations responsible for its publishing. These will include articles in norwegian since this is a region of Europe where many studies have been conducted on kelp forests.

Experts on the subject of the review will be also contacted for provision of unpublished data and for further recommendations.

\section{Search terms will be organized in two groups:}

1. Kelp, Alaria esculenta, Laminaria cucullata, Laminaria digitata, Laminaria flexicaulis,Laminaria hyperborea, Laminaria intermédia, Laminaria ochroleuca, Laminaria rodriguezii, Laminaria saccharina, Laminaria solidungula, Saccorhiza dermatodea, Saccorhiza polyschides, Saccharina latíssima, Undaria pinnatifida. 
2. Foodweb, Fisheries, Fish, Functioning, Canopy removal, Community, Ecology, Nursery, Food, Habitat engineering, Habitat complexity, Harvesting, Removal, Seafood, Shrimps, Shellfish.

All the possible searches containing the combinations between the search terms of the two groups linked with the Boolean operator "AND" will be conducted. For Wok and Scopus all the search terms will be combined in one search using the "AND" or "OR" operator.

The comprehensiveness of the search will be assessed by comparing a list of relevant literature provided by the contacted experts and the results of the databases search. The grey literature to be included in the systematic review will be approved by a group of selected experts prior to inclusion. If necessary, the search strategy will be updated to address problems of missing articles.

\section{Study inclusion criteria}

Different inclusion processes will be followed depending on the type of source of information considered:

Databases information: articles selected by this search will be subjected to a two stage selection to identify the most relevant articles for the review question. If the number of findings is higher than 300 the evaluation of the articles will be based on the title relevance. After this step, the articles will be subjected to a second selection procedure, based on the reading of the abstract. If the number of findings is lower than 300 the titles and abstracts will be read and selected based on the presence of the identified subject and outcome.

Internet information: the first 50 hits of each internet site searched will be selected based on the presence of the identified subject and outcome.

Relevant population: kelp forests including infralitoral and subtidal species.

Exposure: changes in Kelp forest density/area.

Outcome: changes in abundance and diversity of associated species of fishes.

Two reviewers will independently assess a random subset of the articles viewed at full text and the degree of agreement on the quality of the data will be tested statistically using a Kappa test. An appendix will be provided listing those articles excluded at full text along with reasons for exclusion.

\section{Potential effect modifiers and reasons for heterogeneity}

It is expected that there are only few comparable studies with respect to controlled variables, investigated fisheries species, locality, structure of kelp forests etc. Diverse contributors for heterogeneity are listed below. Thus the outcome and final presentation of results cannot be foreseen at the stage of the systematic review planning. It is expected that there will be much qualitative or semiquantitative data and reports that can be used to point out new areas of research and also give first hints on the interrelationship of kelp forests and fisheries along European coastlines. All data should finally be presented in a global context as well.

- differential species life cycle stage of target species (e.g. larvae vs adult shrimp/fish etc.)

- scale of study (one site vs. several sites; spatial extent of investigated sites, short vs long transects)

- habitat structure: species diversity, substrate type, kelp bed structure

- investigated depth gradient of kelp bed $\rightarrow$ extent of depth distribution of kelp forests is dependent on water clarity of locality which may vary considerably between coastlines; this may influence distribution of associated fisheries as well

- nutrient conditions of sites $\rightarrow$ low vs high nutrient conditions may alter the whole food chain

- temperature climate of site (northern vs southern shores) $\rightarrow$ annual temperature climate at investigation sites may strongly influence condition of kelp bed and associated fauna and thereby exert an influence on associated fisheries

- Comparability of sites between studies will often not be given (exposed vs sheltered, northern /southern shores, species inventory of site (algae and invertebrates), temperature conditions, nutrients etc.

- Prey population status (declining, stable, increasing), migratory/non-migratory target species for fisheries

- Comparability of study methodologies.

Table 1 Description of the categories of quality of evidence, organized after adaptation and modification of the guidelines and the hierarchy of evidence quality by Pullin \& Knight [8], Pullin \& Knight [9] and Pullin \& Stewart [10]

\begin{tabular}{cl}
\hline Category & Quality of evidence \\
\hline I & $\begin{array}{l}\text { Evidence obtained from quantitative, random and/or replicated studies. This include quantitative data obtained by estimates of } \\
\text { abundance (biomass and/or percentage cover for seaweeds and abundance for fishes), along randomly chosen and appropriately } \\
\text { replicated transects, sampling points and/or quadrats. }\end{array}$ \\
II & Evidence obtained from quantitative not properly designed studies (failing randomization, replication and control when applicable). \\
III & Evidence obtained from qualitative field evidence, descriptive studies or reports of expert committees. \\
IV $\quad$ Evidence inadequate owing to problems of methodology e.g. sample size, length or comprehensiveness of monitoring or conflicts of \\
scientific evidence.
\end{tabular}




\section{Study quality assessment}

Material found during the search will be categorized according to Table 1 .

Studies from categories I will be selected for meta-analysis and classified based on the quality of the research conducted. This classification will assess the temporal extent of the study, the experimental design, the variables measured and the statistical analysis conducted. Evidence falling in categories II-III will be considered for inclusion in a summarized narrative table describing the study area, design and outcomes of each study. Evidence falling in category IV will not be included in the systematic review. A list of excluded studies and reasons of exclusion will be provided. A table of included studies will be provided detailing decision on quality of each study.

\section{Data extraction strategy}

Relevant studies, based on the inclusion criteria, will be summarized in a table and the following information (if available) will be extracted: author, year, country and study area, studied organisms, methods and main results. Outcome measures will include abundance, presence and diversity of fisheries, mortality, fertility and recruitment rates and feeding behavior.

\section{Data synthesis and presentation}

If enough quantitative high quality data is found, a metaanalysis will be conducted. This analysis will consider only studies reporting on direct relationship between changes in kelp forests density and/or area in fisheries. Studies carried out in a single year do not provide sufficient data to calculate statistics for inclusion in a meta-analysis and thus will be excluded. Regardless of whether or not the quality of data is high enough to conduct a metaanalysis the outcomes of the studies will be summarized in narrative tables including information on the study area, study design, intervention, variables measured, analysis performed and quality assessment for each study.

\section{Competing interests}

The authors declare that they have no competing interests.

\section{Authors' contributions}

RA participated in the conception and design of the study and drafted the manuscript. IB contributed to the design of the study and critically revised the manuscript. TB contributed to the design of the study and critically revised the manuscript. KE critically revised the manuscript. ISP conceived the study and the design and critically revised the manuscript. All authors read and approved the final manuscript.

\section{Acknowledgements}

We would like to acknowledge the advice of Andrew Pullin and Barbara Livoreil on systematic review methodologies. We are grateful to Stefan Schindler and Luis Santamaria for discussions on the setting of the KNEU test cases. We would like also to acknowledge the involvement of Ricardo Aguillar, Jorge Assis, Jose Rico, Elisabeth Strain and Laura Airoldi in the delineation of the marine test case study.

\section{Author details}

${ }^{1}$ Centre of Marine and Environmental Research, University of Porto (CIMAR-Porto), Rua dos Bragas, 289, 4050-123 Porto, Portugal.

${ }^{2}$ Alfred-Wegener Institute, Helmholtz Centre for Polar and Marine Research, Am Handelshafen 12, 27570 Bremerhaven, Germany. ${ }^{3}$ Norwegian Institute of Water Research, Gaustadalleen 21, N-0349 Oslo, Norway. ${ }^{4}$ University of Oslo, Natural History Museum, Box 1172 Blindern, N-0318 Oslo, Norway. ${ }^{5}$ University of Algarve, Center of Marine Sciences, CCMAR, P8005139 Faro, Portugal. ${ }^{6}$ Department of Biology, Faculty of Sciences, University of Porto, Rua do Campo Alegre, s/n, 4050 Porto, Portugal.

Received: 18 February 2013 Accepted: 16 July 2013

Published: 31 July 2013

\section{References}

1. Crowder L, Norse E: Essential ecological insights for marine ecosystem-based management and marine spatial planning. Marine Policy 2008, 32:772-778.

2. Steneck RS, Graham MH, Bourque BJ, Corbett D, Erlandson JM, Estes JA, Tegner MJ: Kelp forest ecosystems: biodiversity, stability, resilience and future. Environ Conserv 2002, 29(4):436-459.

3. Lorentsen SH, Sjotun K, Gremillet D: Multi-trophic consequences of kelp harvest. Biol Conserv 2010, 143(9):2054-2062.

4. Graham MH: Effects of local deforestation on the diversity and structure of Southern California giant kelp forest food webs. Ecosystems 2004, 7(4):341-357.

5. Norderhaug KN, Christie H, Fossa JH: Fish-macrofauna interactions in a kelp (Laminaria hyperborea) forest. J Mar Biol Assoc U K 2005, 85(5):1279-1286.

6. Reisewitz SE, Estes JA, Simenstad CA: Indirect food web interactions: sea otters and kelp forest fishes in the Aleutian archipelago. Oecologia 2006, 146(4):623-631.

7. Fujita RM, Foran T, Zevos I: Innovative approaches for fostering conservation in marine fisheries. Ecol App/ 1998, 8(1):139-150.

8. Pullin AS, Knight TM: Effectiveness in conservation practice: pointers from medicine and public health. Conserv Bio/ 2001, 15:50-54.

9. Pullin AS, Knight TM: Support for decision making in conservation practice: An evidence-based approach. J Nat Conserv 2003, 11:83-90.

10. Pullin AS, Stewart GB: Guidelines for systematic review in conservation and environmental management. Conserv Biol 2006, 20(6):1647-1656.

doi:10.1186/2047-2382-2-15

Cite this article as: Araujo et al:: What is the impact of kelp forest density and/or area on fisheries?. Environmental Evidence 2013 2:15.

\section{Submit your next manuscript to BioMed Central and take full advantage of:}

- Convenient online submission

- Thorough peer review

- No space constraints or color figure charges

- Immediate publication on acceptance

- Inclusion in PubMed, CAS, Scopus and Google Scholar

- Research which is freely available for redistribution 